\title{
Papers
}

\section{Life span and disability: a cross sectional comparison of Russian and Swedish community based data}

\author{
Martin Bobak, Margareta Kristenson, Hynek Pikhart, Michael Marmot
}

\begin{abstract}
Objectives To compare levels of disability (in terms of physical function and self rated health) among middle aged and elderly people in Russia and Sweden, a country with high life expectancy.

Design Cross sectional study.

Setting General population of the Russian Federation and of two counties in southern Sweden.

Participants Randomly selected men and women in Sweden $(\mathrm{n}=9489)$ and Russia $(\mathrm{n}=1599)$.

Main outcome measures Official life table data; self rated health and physical functioning (subscale of the SF-36).

Results The official life table data showed large differences in mortality-for example, $36 \%$ of Russian men aged 45 - 49 years would survive the next 25 years compared with $75 \%$ of Swedish men. The survey data showed, for both sexes, similar levels of self rated health and physical functioning in the two countries up to the age of about 45 years, but after that, the age related decline in both outcomes was much faster in Russia than in Sweden. By combining the national life tables with survey data on physical functioning we estimated that in the age group 45-49 years, 99\% of Russian and 97\% of Swedish men would be free of disability; of these, if these data were for a cohort, only $17 \%$ of Russians would be alive and free of disability 25 years later compared with $65 \%$ of Swedes. The difference in survival was similar in women.

Conclusions Large differences exist in survival without disability between elderly Russians and Swedes. The short life span in Russia reflects high levels of ill health and disability and is associated with a rapid age related decline in physical functioning.
\end{abstract}

\section{Introduction}

Life expectancy in Russia is considerably lower than in western Europe. $^{12}$ Some of the excess mortality is due to injuries, violence, and alcohol misuse, ${ }^{12}$ but the high mortality in Russia persists into older age groups, where these causes of death are much less common. So far, data on rates of non-fatal outcomes in Russia have been available for cardiovascular diseases ${ }^{3}{ }^{4}$ but not for health conditions specific to elderly people, such as impaired functioning or disability. Such information is important to assess the rates of ill health in elderly people, which pose a heavy burden for health and social services.

Studying the health status of the Russian population may also be relevant to the more general question of whether increased life expectancy is associated with high rates of disability in elderly people. The morbidity compression hypothesis pre- dicts that with increasing life span the cumulative length of time spent with disability becomes smaller ${ }^{5-7}$ By contrast, data from the Indian state of Kerala seem to suggest the opposite. ${ }^{8}$ One way to contribute to this debate is to compare identical measures of health and functional status in populations with different life expectancies. Although the morbidity compression hypothesis has not been applied to differences between countries, one would expect that countries with high life expectancy, such as Sweden, would have lower rates of disability among elderly people than countries with low life expectancy, such as Russia.

We compared data on self rated health and physical functioning in community based population samples in Russia and southern Sweden to examine whether the high mortality in Russia is reflected in poor health among elderly people, and, if so, what are the implications for survival without disability.

\section{Methods}

\section{Sources of data}

We used official life tables for Russia and Sweden in 1996, based on national mortality data reported to the World Health Organization, from the WHO online database. ${ }^{9}$ We used data on the number of people alive in a given five year age group in the life table population to assess survival in each country. Data on self rated health and physical functioning were taken from cross sectional surveys in random population samples.

The Russian data came from the 1996 New Russia Barometer (NRB) survey of a random sample of people aged $\geq 18$ years selected in a multi-stage sampling process. ${ }^{10}$ Firstly, the Russian Federation was stratified into large regions. Secondly, 69 urban and rural settlements were selected with a probability equal to their share of the population. Thirdly, primary sampling units (enumeration districts) were randomly drawn within each settlement. Fourthly, within each primary sampling unit, households were listed by address, and interviewers were instructed to seek an interview at every nth house. At each address the interviewer asked for a respondent matching an age $\times$ sex $\times$ education grid. Of 3379 households with someone at home, in 965 cases no one met the requirements of the sample grid. Of the 2414 remaining households, in 741 (31\%) the interview was refused, in $63(3 \%)$ the identified individual was unable to answer, and 11 interviews $(0.4 \%)$ were interrupted. The 1599 completed interviews represent a final response rate of $66 \%$. The participants completed an interview that covered a wide range of sociodemographic variables, attitudes towards the political and economic changes, and self rated health and physical functioning.

In 1999 a random population sample completed a postal population survey in two counties in southern Sweden: 
Östergötland and Kalmar. The samples were drawn from the Swedish Statistical Population Register; the fraction sampled in both cases was about $4 \%$ of the general population aged 20 to 74 years. Of the 16000 people selected for the study, 506 had moved out of the region or died. After the exclusion of incomplete questionnaires, 9489 people were included in the following analyses (response rate 59\%). Apart from lower than expected proportion of immigrants and unmarried or cohabiting people, the social characteristics of the respondents were similar to the general population of the two counties. The survey included a wide range of questions on sociodemographic and lifestyle characteristics and health.

\section{Health variables}

Both countries used identical questions on health. Self rated health was assessed by the question "How do you rate your health in general?" with responses at 5 point scale. We combined the two lowest categories ("bad" and "very bad") into "poor health" in our analysis. Physical functioning was measured by 10 questions included in the SF-36. ${ }^{11}{ }^{12}$ The questions cover limitations in several everyday activities (for example, shopping, bathing, walking, etc). We used a standard algorithm to calculate an overall physical functioning score with values from 0 (total disability) to 100 (full functioning); "low physical functioning" was defined as score less than 60 .

\section{Statistical analyses and presentation of results}

Firstly, we plotted the official survival probabilities for Sweden and Russia by five year age groups, separately for men and women, for all ages and for ages 45-49 years onwards, with the age group 45-49 years as baseline. Secondly, we plotted the prevalence of poor self rated health and the mean physical functioning score in Russia and Sweden by the same five year age group, separately for men and women. As using weights to correct for the differences between the age-sex-educational distribution of the Russian sample and the Russian Federation did not change the findings, we have reported the unweighted results. Finally, we estimated survival without disability between ages 45-49 years and 70-74 years by multiplying, in each five year age group, the proportion of survivors by the proportion of people without disability (physical functioning score at least 60), taking the number of healthy people in the $45-49$ years age group as baseline.

\section{Results}

The official life tables showed that mortality in those aged $<45$ years was much higher in Russia than in Sweden. In Russia, 80\% of males and $93 \%$ of females survived from birth to age 45 years compared with $97 \%$ and $98 \%$ in Sweden, respectively (data not shown). However, differences in mortality at older ages were also large, as documented by survival curves from the age group 45-49 years (fig 1). If these life table estimates were applied to a cohort, only $36 \%$ of Russian men $45-49$ years old would survive the next 25 years compared to $75 \%$ of Swedes; similarly, $34 \%$ of Russian men aged 70-74 years would survive another 10 years compared with $57 \%$ of similarly aged men in Sweden. The differences in survival between Russian and Swedish women were smaller but also clearly marked.

Figure 2 and the table show prevalence of poor self rated health in the two surveys: in a national Russian population sample and in a community sample in southern Sweden. Until the age of about 55-59 years in men and 50-54 years in women, the prevalence of poor health is similar in the two populations. After those ages, the rates of poor health remain about stable in Swe-

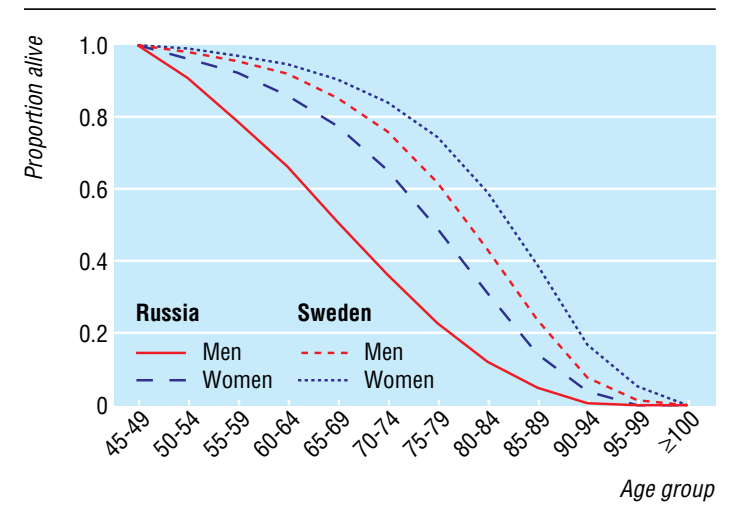

Fig 1 Proportion of people alive in each five year age group, relative to age group 45-49 years, in Russian and Swedish men and women (based on national life tables)

den but increase rapidly with age in Russia. Physical functioning shows a similar picture (fig 3 and table). The mean scores were similar until the age group 45-49 years in men and 35-39 years in women but thereafter the decline with age was much faster in Russia than in Sweden. In both sexes, the slopes of age related decline in health and functioning were significantly steeper in Russia than in Sweden (all P values $<0.001$ ).

In the age group $45-49$ years, $99 \%$ of Russian men and $97 \%$ of Swedish men and $89 \%$ of Russian women and $94 \%$ of Swedish women were free of disability. By combining the life tables with the survey data, we estimated the proportion of people both alive and without disability between the ages of 45-49 and 70-74 years in each country, relative to the 45-49 year age group (fig 4). The differences between Russia and Sweden were remarkable. Assuming again that these were data for a cohort, $65 \%$ of healthy 45-49 year old Swedish men would be alive and without disability 25 years later compared with only $17 \%$ of Russian men. The
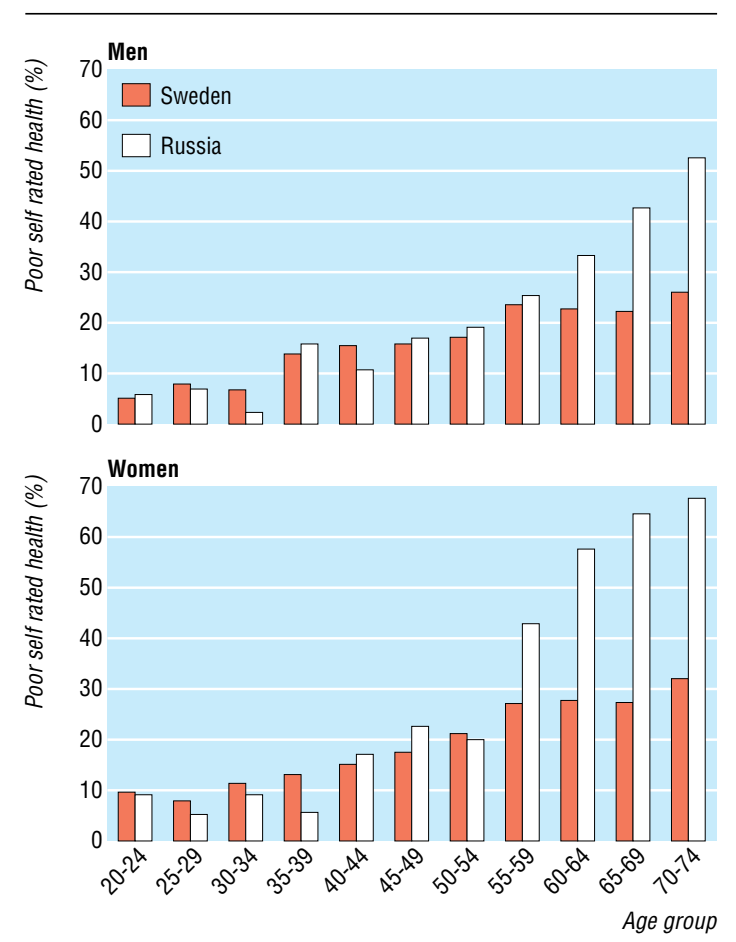

Fig 2 Prevalence of poor self rated health by age group and sex in Russia and Sweden 
Age specific differences in self rated health and physical functioning between Russia and Sweden, with $95 \%$ confidence intervals

\begin{tabular}{|c|c|c|c|c|c|c|}
\hline \multirow[b]{2}{*}{ Age group } & \multicolumn{3}{|c|}{ Men } & \multicolumn{3}{|c|}{ Women } \\
\hline & Sweden & Russia & Difference $(95 \% \mathrm{CI})^{*}$ & Sweden & Russia & Difference $(95 \% \mathrm{Cl})^{*}$ \\
\hline \multicolumn{7}{|c|}{ Poor self rated health (\%) } \\
\hline $20-24$ & 4.8 & 5.6 & $-0.8(-6.6$ to 5.0$)$ & 9.8 & 9.2 & $0.6(-6.5$ to 7.6$)$ \\
\hline $25-29$ & 7.3 & 6.5 & $0.8(-5.3$ to 6.9$)$ & 8.7 & 5.3 & $3.4(-2.9$ to 9.8$)$ \\
\hline $30-34$ & 6.2 & 1.8 & 4.4 (1.7 to 8.6$)$ & 11.3 & 9.1 & $2.2(-5.3$ to 9.7$)$ \\
\hline $35-39$ & 13.8 & 15.7 & $-1.9(-11.1$ to 7.3$)$ & 13.1 & 5.5 & 7.6 (2.0 to 13.2$)$ \\
\hline $40-44$ & 15.2 & 10.3 & $4.9(-2.1$ to 12.0$)$ & 15.3 & 17.3 & $-2.0(-10.8$ to 6.9$)$ \\
\hline $45-49$ & 15.6 & 16.7 & $-1.1(-10.4$ to 8.2$)$ & 17.8 & 22.8 & $-5.0(-14.2$ to 4.2$)$ \\
\hline $50-54$ & 17.0 & 19.0 & $-2.0(-11.2$ to 7.3$)$ & 21.1 & 20.0 & $1.1(-8.5$ to 10.8$)$ \\
\hline $55-59$ & 23.2 & 25.5 & $-2.3(-14.8$ to 10.3$)$ & 27.1 & 42.9 & $-15.8(-27.0$ to -4.5$)$ \\
\hline $60-64$ & 22.4 & 33.3 & $-10.9(-24.2$ to 2.3$)$ & 27.7 & 57.1 & $-29.4(-41.8$ to -17.1$)$ \\
\hline $65-69$ & 22.2 & 42.5 & $-20.3(-36.3$ to -4.4$)$ & 27.6 & 64.8 & $-37.2(-49.1$ to -25.3$)$ \\
\hline $70-74$ & 26.0 & 52.4 & $-26.4(-48.3$ to -4.5$)$ & 32.2 & 67.4 & $-35.2(-50.1$ to -20.3$)$ \\
\hline \multicolumn{7}{|c|}{ Physical functioning (mean score) } \\
\hline $20-24$ & 95.6 & 95.6 & $0.0(-4.2$ to 4.2$)$ & 96.1 & 96.1 & $0.0(-4.4$ to 4.3$)$ \\
\hline $25-29$ & 97.4 & 94.2 & $3.1(-2.7$ to 8.9$)$ & 94.4 & 94.1 & $0.3(-6.3$ to 6.9$)$ \\
\hline $30-34$ & 95.1 & 96.5 & $-1.4(-7.6$ to 4.8$)$ & 92.8 & 91.1 & $1.8(-4.6$ to 8.2$)$ \\
\hline $35-39$ & 93.6 & 93.9 & $-0.2(-6.1$ to 5.7$)$ & 91.8 & 90.4 & $1.4(-4.6$ to 7.3$)$ \\
\hline $40-44$ & 94.0 & 92.4 & $1.5(-4.0$ to 7.1$)$ & 91.1 & 84.7 & 6.5 (0.4 to 12.6) \\
\hline $45-49$ & 92.2 & 93.1 & $-0.9(-6.7$ to 5.0$)$ & 88.9 & 79.8 & 9.1 (3.2 to 15.0) \\
\hline $50-54$ & 91.5 & 85.4 & 6.0 (0.3 to 11.7) & 85.6 & 77.1 & 8.6 (2.4 to 14.7) \\
\hline $55-59$ & 86.5 & 83.1 & $3.4(-2.9$ to 9.8$)$ & 81.4 & 66.7 & 14.7 (8.7 to 20.8) \\
\hline $60-64$ & 82.8 & 67.7 & 15.2 (8.9 to 21.4) & 78.5 & 61.7 & 16.9 (10.5 to 23.2) \\
\hline $65-69$ & 83.2 & 67.9 & 15.3 (8.5 to 22.1) & 73.4 & 53.4 & 20.0 (13.7 to 26.4) \\
\hline $70-74$ & 76.3 & 61.4 & 14.9 (6.5 to 23.2) & 68.1 & 46.9 & 21.2 (13.9 to 28.4) \\
\hline
\end{tabular}

${ }^{*} \mathrm{P}<0.001$ for increase in difference between populations with increasing age for both end points in both sexes.

difference was similar among women: $65 \%$ in Sweden compared with 22\% in Russia. The differences between the two countries were due to high rates of both death and disability in Russia, with death rate contributing more to differences in men and disability rate more to differences in women (fig 5 ).
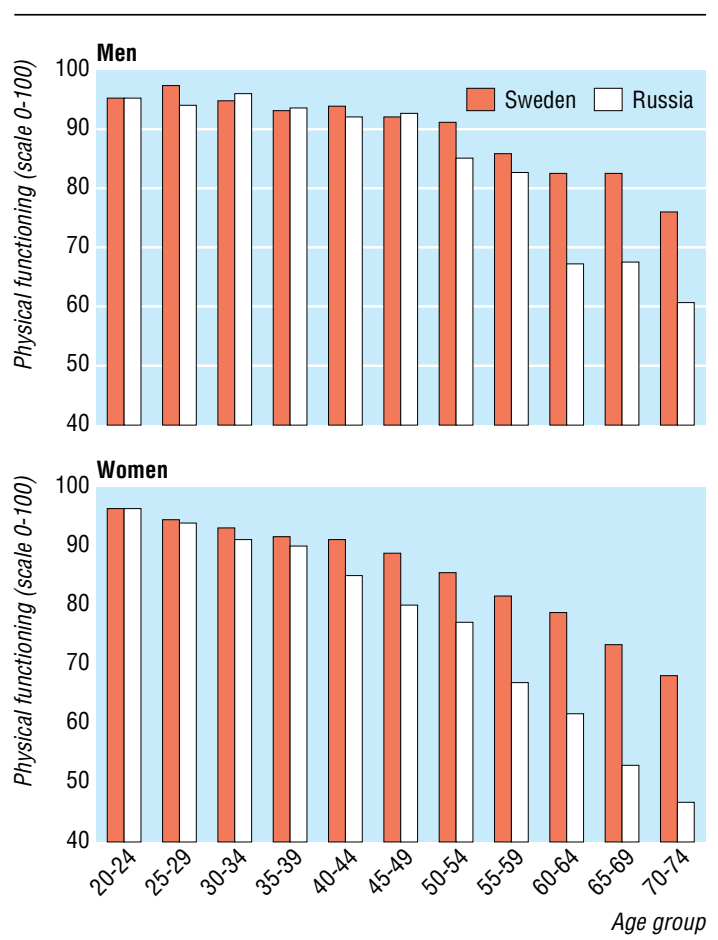

Fig 3 Mean score of physical functioning by age group in Russian and Swedish men and women

\section{Discussion}

In these cross sectional data, we found a much steeper age related decline in health and functioning in Russia than in Sweden, resulting in much worse health and functional status in elderly Russians compared with elderly Swedes. The combination of high mortality and high disability results in a huge difference in the estimated survival without disability in people from their late 40 s to mid-70s between the two countries.

Though self rated health is a purely subjective measure, physical functioning score is based on 10 relatively specific questions and is less prone to reporting bias. The SF-36, the source of the questions on physical functioning, has been validated against clinical end points in many populations, including Russian. We also considered the possibility that the different methodology (interviews in Russia and postal survey in Sweden) could have led to differential reporting of disability. One would expect that such bias would affect all age groups. However, the levels of both

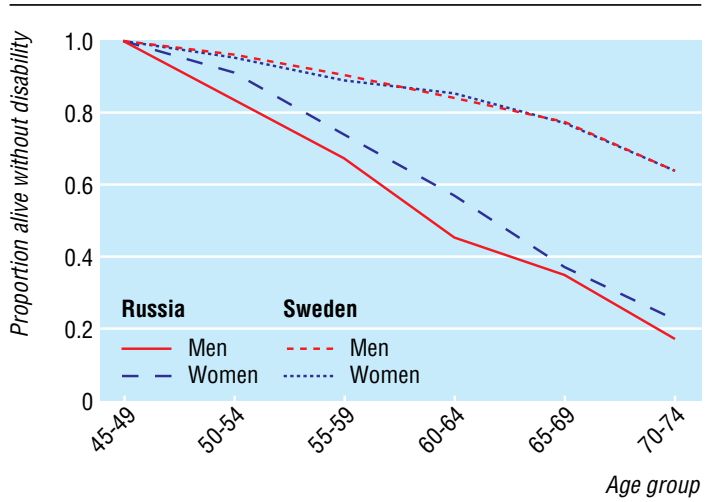

Fig 4 Survival without disability between ages 45-49 and 70-74 years in Russian and Swedish men and women 


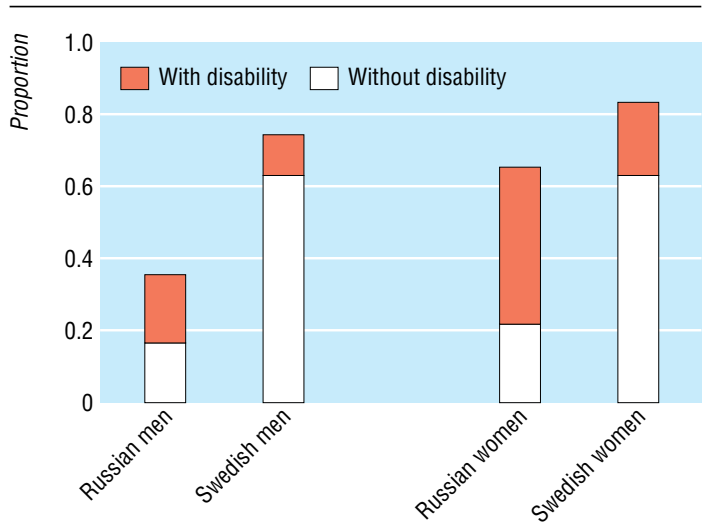

Fig 5 Total survival and survival without disability to age 70-74 years among men and women without disability at age $45-49$ years (proportions)

self rated health and physical functioning were similar in the two populations in younger people and only started to diverge after the age of 40 or 50 years. At least for self rated health, the rates of poor health in this study are, if anything, higher than in a Swedish national interview study of people aged 55-74 years. ${ }^{13}$ In another survey comparing 50 year old men in Sweden and Lithuania, which used slightly different terminology, the differences in self rated health were even larger, with $7 \%$ of Swedes and $45 \%$ of Lithuanians reporting health as "not very good" or "not good at all."14 This argues against under-reporting of ill health in Sweden in our study. Moreover, as expected, the differences between the two countries varied by sex, being mainly due to mortality in men but disability in women. All this strongly suggests that the differences in health and physical functioning between the Russians and Swedes are genuine, rather than a methodological artefact.

One issue with survival without disability and healthy life expectancy is that they are based on data from people with a particular history that may not be applicable to other populations or cohorts. For example, the health status of 70 year old Russians may reflect wartime conditions-this may be particularly important given the increasingly recognised importance of effects throughout life. ${ }^{15}$ Extrapolation to future cohorts may therefore be problematic, and the interpretation of our results needs to be cautious. We have focused on temporary differences between the two countries and have refrained from explicit predictions of future survival.

Our findings are consistent with results from the WHO healthy life expectancy project. ${ }^{16}{ }^{17} \mathrm{On}$ the basis of different data and methods, the healthy (that is, free of disability) life expectancy at age 60 years was 16.5 years in Swedish men and 8.5 years in Russian men; among women the figures were 18.5 and 12.7 years, respectively. These results show that the low life expectancy in Russia does not provide a full picture of the burden of ill health, as represented by the high rates of poor health and disability in this study and high rates of non-fatal cardiovascular disease reported by others. ${ }^{12}$ The alarming rates of disability in older men and women show that the health crisis in Russia is not confined to middle aged men. More generally, our data are consistent with recent evidence suggesting a decline of lifetime morbidity with increasing longevity. ${ }^{7}$ While this cross sectional comparison cannot replace longitudinal studies of the changes in mortality and health, the results support the view that extending length of life does not necessarily lead to high rates of disability at older ages.

\section{What is already known on this topic}

Russia has one of the lowest life expectancies in the industrialised world

Most attention has been given to death rates of middle age men with little interest in the health of older people in Russia

Disability levels in Russia have not been systematically studied

\section{What this study adds}

High levels of disability exist in elderly Russians

The age related decline in health and physical functioning is much faster in older men and women in Russia than in Sweden

In middle aged and older Russians survival without disability is about one third of that in Sweden

We thank Michael Murphy for valuable comments on various drafts of the paper and the European Scientific Foundation scientific programme on social variations in health expectancy in Europe for useful discussions.

Contributors: $\mathrm{MB}$ and $\mathrm{MK}$ jointly developed the principal idea and MB drafted the paper. HP analysed the data and commented on the draft. MM contributed to the discussions of the principal ideas and commented on the draft. MB is the guarantor.

Funding: The Swedish study was funded by the County Council of Östergötland and performed by the LinQuest group at the Centre of Public Health Sciences in Linköping. The New Russia Barometer survey was maintained by the Centre for the Study of Public Policy (led by Richard Rose), University of Strathclyde, and funded by the Paul Lazarsfeld Society, Vienna, and the MacArthur Foundation. The analyses were supported by grants from the Wellcome Trust and by the MacArthur Foundation Initiative on Social Upheaval and Health. MM is the recipient of an MRC Research Professorship. The funders had no role in the design, conduct, analysis, or interpretation of the study.

Conflict of interest: None declared.

Ethical approval: The Swedish survey was approved by the ethical committee of the University of Linköping. The Russian survey was of non-medical nature and ethical approval was not required.

1 Leon DA, Chenet L, Shkolnikov V, Zakharov S, Shapiro J, Rakhmanova G, et al. Huge variation in Russian mortality rates 1984-94: artefact, alcohol, or what? Lancet variation in Russize $1997 ; 350: 383-8$.

2 Notzon FC, Komarov YM, Ermakov SP, Sempos CT, Marks JS, Sempos EV. Causes of declining life expectancy in Russia. JAMA 1998;279:793-800.

3 Tunstall-Pedoe H, Kuulasmaa K, Amouyel P, Arveiler D, Rajakangas AM, Pajak A. Myocardial infarction and coronary deaths in the World Health Organization MONICA project. Registration procedures, event rates, and case-fatality rates in 38 populations from 21 countries in four continents. Circulation 1994;90:583-612.

4 Tunstall-Pedoe H, Kuulasmaa K, Mahonen M, Tolonen H, Ruokokoski E, Amouyel P, et al. Contribution of trends in survival and coronary event rates to changes in coronary heart disease mortality: 10 year results from 37 WHO MONICA project populations. Lancet 1999;353:1547-57.

5 Fries JF. Aging, natural death, and the compression of morbidity. $N$ Engl J Med 1980;303:130-5,

6 Kalache A, Aboderin I, Hoskins I. Compression of morbidity and active ageing: key priorities for public health policy in the 21st century. Bull World Health Organ 2002;80:243-4.

7 Fries JF. Measuring and monitoring success in compressing morbidity. Ann Intern Med 2003;139:455-9.

8 Sen A. Health: perception versus observation. BMJ 2002;324:860-1

9 World Health Organization. WHO Statistical Information System (WHOSIS). Evidence and information for health policy. www3.who.int/whosis (accessed 30 March 2004).

10 Bobak M, Pikhart H, Hertzman C, Rose R, Marmot M. Socioeconomic factors, perceived control and self-reported health in Russia. A cross-sectional survey. Soc Sci Med 1998;47:269-279.

11 Ware JE, Sherbourne CD. The MOS 36-item short-form health survey (SF-36). I. Conceptual framework and item selection. Med Care 1992;30:473-83.

12 McHorney CA, Ware JE, Raczek AE. The MOS 36-item short-form health survey (SF36): II. Psychometric and clinical tests of validity in measuring physical and mental health constructs. Med Care 1993;31:247-63. 
13 Pudaric S, Sundquist J, Johansson SE. Country of birth, instrumental activities of daily living, self-rated health and mortality: a Swedish population-based survey of people aged 55-74. Soc Sci Med 2003;56:2493-503.

14 Kristenson M, Kucinskiene Z, Bergdahl B, Calkauskas H, Urmonas V, Orth-Gomer K. Increased psychosocial strain in Lithuanian versus Swedish men: the LiVicordia Study. Psychosom Med 1998;60:277-82.

15 Kuh D, Ben-Shlomo Y, eds. A life course approach to chronic disease epidemiology. Oxford: Oxford University Press, 1997.

16 Mathers CD, Sadana R, Salomon JA, Murray CJL, Lopez AD. Healthy life expectancy in 191 countries, 1999. Lancet 2001;357:1685-91.

17 World Health Organization. Healthy life expectancy. www3.who.int/whosis/hale/ hale.cfm? path $=$ whosis,burden_statistics,hale\&language $=$ english $($ accessed $30 \mathrm{March}$

(Accepted 26 July 2004) doi 10.1136/bmj.38202.667130.55

International Centre for Health and Society, University College London, London WC1E 6BT

Martin Bobak senior lecturer

Hynek Pikhart research fellow

Michael Marmot director

Department of Health and Society, Faculty of Health Sciences, University of Linköping, Sweden S-58183

Margareta Kristenson senior lecturer

Correspondence to: M Bobak m.bobak@ucl.ac.uk 